bury Public Health Laboratory; South Shields General Hospital; St Mary's Hospital, London; St Richard's Hospital, Chichester St Andrew's Hospital, London; St Thomas's Hospital, London Stoke Mandeville Hospital; Stoke on Trent Public Health Laboratory; Sunderland District General Hospital; Swansea Public Health Laboratory; The London Hospital Medical School Tooting Public Health Laboratory; University College Hospital; Watford Public Health Laboratory; West Midland Regional Blood Transfusion Service; West Suffolk Hospital; Whipps Cross Public Health Laboratory; Whittington Hospital; Wolverhampton Public Health Laboratory; Wycombe General Hospital; York District Hospital.

1 Clarke M, Seagroatt V, Schild GC, et al. Surveys of antibodies in young adults and children. Lancet 1983;i:667.
2 Naish J. Rubella immunity in pregnant women in a north London practice. BrMed f 1984;288:1053.

3 Foster W. An opportunistic approach to rubella screening in general practice. 7R Coll Gen Pract 1986;36:58-60.

4 Gilmore D, Robinson ET, Gilmour WH, et al. Effect of rubella vaccination programme in schools on rubella immunity in a general practice population BrMed f 1982;284:628-30.

5 Rowlands S, Bethel RGH. Rubella vaccination: screening all women at risk. Br Med F 1981;283:829-31.

Miller CL, Miller E, Sequeira PJL, et al. Effect of selective vaccination on rubella susceptibility and infection in pregnancy. $\mathrm{Br}$ Med $\mathcal{F}$ 1985;291:1398401

7 Miller CL, Miller E, Waight PA. Rubella susceptibility and the continuing risk of infection in pregnancy. Br Med f 1987;294:1277-8.

8 Peckham CS, Marshall WC, Dudgeon JA, et al. Rubella vaccination of schoolgirls: factors affecting vaccine uptake. Br Med f 1977; i:760-1.

Accepted 16 August 1988)

\title{
Adverse neurodevelopmental outcome of moderate neonatal hypoglycaemia
}

\author{
A Lucas, R Morley, T J Cole
}

\begin{abstract}
There has been considerable debate over whether asymptomatic neonatal hypoglycaemia results in neurological damage. In a detailed multicentre study of 661 preterm infants hypoglycaemia was found to be common. Moderate hypoglycaemia (plasma glucose concentration $<2.6 \mathrm{mmol} / \mathrm{l}$ ) occurred in 433 of the infants and in 104 was found on three to 30 separate days. There was considerable variation among the centres, implying differences in decisions to intervene. The number of days on which moderate hypoglycaemia occurred was strongly related to reduced mental and motor development scores at 18 months (corrected age), even after adjustment for a wide range of factors known to influence development. When hypoglycaemia was recorded on five or more separate days adjusted mental and motor developmental scores at 18 months (corrected age) were significantly reduced by 14 and 13 points respectively, and the incidence of neurodevelopmental impairment (cerebral palsy or developmental delay) was increased by a factor of 3.5 (95\% confidence interval 1.3 to 9.4 ).

These data suggest that, contrary to general belief, moderate hypoglycaemia may have serious neurodevelopmental consequences, and reappraisal of current management is urgently required.
\end{abstract}

\section{Introduction}

There is considerable debate over what should be chosen as a safe lower limit for blood glucose concentration in the neonatal period..$^{1-3}$ Glucose is the principal substrate for cerebral metabolism, and neonatal hypoglycaemia can cause damage to both neuronal and glial cells, resulting in severe handicap or death..$^{4-9}$ Nevertheless, newborn infants have been regarded as fairly resistant to the pathophysiological effects of hypoglycaemia because they often remain asymptomatic at blood glucose concentrations low enough to cause severe symptoms in adults. ${ }^{8.13}$ Such asymptomatic hypoglycaemia has been claimed to have a good prognosis, ${ }^{814-18}$ suggesting that alternative metabolic substrates for the brain may be available in early life. ${ }^{3}$ To exclude the possibility that asymptomatic and moderate hypoglycaemia may cause persistent adverse effects on neurodevelopment, however, requires large numbers of subjects, and available data do not provide adequate reassurance, particularly in infants born before term, in whom hypoglycaemia is common. ${ }^{19} 20$
We examined the incidence and antecedents of low blood glucose concentrations in 661 infants of low birth weight and related the occurrence and persistence of hypoglycaemia to the neurodevelopmental outcome at 18 months after term in 543 survivors.

\section{Subjects and methods}

We studied 661 preterm infants who weighed less than $1850 \mathrm{~g}$ at birth and survived the first 48 hours of life. Their mean (SD) birth weight was 1337 (315) g, and their mean gestational age was $30.5(2.7)$ weeks; those with major congenital abnormalities were excluded. The infants, who were taking part in a large study of feeding conducted at five centres, ${ }^{21}$ were a major unselected subsample of those for whom plasma glucose monitoring had been planned. Extensive demographic, obstetric, and neonatal data were available.

Weekly plasma samples were taken from the infants and analysed for glucose. In addition, glucose concentrations were determined with reagent sticks every six hours for the first 48-72 hours. Generally, infants with a blood glucose concentration on stick testing below $1.5 \mathrm{mmol} / \mathrm{l}$ or with two or more values below $2 \cdot 0-2 \cdot 5 \mathrm{mmol} / 1$ received a blood test to determine their plasma glucose concentration. All infants requiring intensive care (most of them) were monitored daily for plasma glucose concentration, regardless of the values on stick testing. This daily sampling continued until the infant was clinically stable, often into the second or third week. Only data from the plasma samples are reported in this study; these samples were analysed by the glucose oxidase method. Data from 6808 samples taken on separate days are presented. The study continued until the infants were discharged or weighed $2000 \mathrm{~g}$, whichever occurred first. All infants were studied in the first week; the number still remaining in the study declined with postnatal age, falling to 428 , 260,127 , and 59 infants by the third, fifth, seventh, and ninth weeks respectively.

Early feeding practices in the centres were broadly similar. Enteral feeding started before 2 hours in large, well babies, and in ill babies and those not tolerating feeds an intravenous infusion of glucose was established immediately, progressing within 48 hours to an incremental regimen to provide total parenteral nutrition. In four of the units intravenous nutrition was accompanied by minimal enteral feeding as soon as the infant's condition was stable. In one unit (centre B), however, small, sick babies usually had elective 
intravenous nutrition without enteral feeds for about two weeks. Hypoglycaemia was treated by increasing the rate of delivery of glucose; in addition, an initia bolus of glucose was given when the plasma glucose concentration was $<1.0 \mathrm{mmol} / 1$ or thought to be causing symptoms and when hypoglycaemia was associated with an episode of acute asphyxia. Doctors in each centre had varied opinions on the degree of hypoglycaemia warranting intervention ( $\mathrm{T} \mathrm{H} \mathrm{H} \mathrm{G}$ Koh, unpublished data), and centres differed in this respect - for example, in centre $D$ intervention tended to be at a lower plasma glucose concentration (often under $1.5 \mathrm{mmol} / \mathrm{l}$ ) than in centre $\mathrm{B}$, where infants with a concentration of $2 \cdot 0-2 \cdot 5 \mathrm{mmol} / \mathrm{l}$ were treated.

At 18 months after the expected date of birth mothers were invited to take their infants to a follow up clinic, where assessment included a detailed neurological examination and application of the Bayley motor and mental development scales. ${ }^{22}$ One of us (RM) conducted this examination in four of the five centres. In all cases the investigator was blind to the findings in the neonatal period. Altogether 543 infants were assessed in this way, representing a $92 \%$ follow up of survivors.

Approval for the study was obtained from the health authority's ethical committee for each of the five centres and from the nutrition unit's own ethical committee. Statistical analysis included the $\chi^{2}$ test, Student's $t$ test, multiple regression for continuous dependent variables, and logistic regression for dichotomous dependent variables.

\section{Results}

\section{OCCURRENCE OF HYPOGLYCAEMIA}

Table I shows the occurrence of plasma glucose concentrations $<0 \cdot 6,<1 \cdot 6$, or $<2.6 \mathrm{mmol} / \mathrm{l}$ and the number of days on which these concentrations were recorded in the 661 babies. Severe hypoglycaemia $(<0.6 \mathrm{mmol} / \mathrm{l})$, seen in 65 infants, seldom occurred on more than one day. In contrast plasma glucose concentrations $<2.6 \mathrm{mmol} / \mathrm{l}$, found in 433 infants, were often seen over prolonged periods: 104 infants $(16 \%)$ had such concentrations on three to 30 separate days. Infants weighing $<1000 \mathrm{~g}$ at birth had a substantially greater occurrence of all degrees of hypoglycaemia than heavier babies $(\mathrm{p}<0.001)$, and $46(39 \%)$ had a blood glucose concentration $<2.6 \mathrm{mmol} / \mathrm{l}$ on three or more days. Preterm infants who were small for gestational age also constituted a high risk group for hypoglycaemia: $43(21 \%)$ had a glucose concentration of $<2.6 \mathrm{mmol} / \mathrm{l}$ on three or more days.

As sampling was discontinuous the occurrence of

TABLE I - Number (percentage) of preterm infants of birth weigh $<1850 \mathrm{~g}$ with hypoglycaemia and number of days on which it was recorded

\begin{tabular}{|c|c|c|c|}
\hline & \multicolumn{3}{|c|}{ Plasma glucose $(\mathrm{mmol} / \mathrm{l})$} \\
\hline & $<0 \cdot 6$ & $<1 \cdot 6$ & $<2 \cdot 6$ \\
\hline \multicolumn{4}{|c|}{ Whole population $(n=661)$} \\
\hline Occurrence & $65(9 \cdot 8)$ & $186(28 \cdot 1)$ & $433(66 \cdot 5)$ \\
\hline \multicolumn{4}{|c|}{$\begin{array}{l}\text { No of days on which concentration } \\
\text { recorded: }\end{array}$} \\
\hline 1 & $52(8)$ & $135(20)$ & $211(32)$ \\
\hline 2 & $4(1)$ & $25(4)$ & $118(18)$ \\
\hline$\geqslant 3^{\star}$ & $9(1)$ & $26(4)$ & $104(16)$ \\
\hline$\geqslant 7 \star$ & $2(0)$ & $6(1)$ & $20(3)$ \\
\hline$\geqslant 14^{\star}$ & & $2(0)$ & $6(1)$ \\
\hline \multicolumn{4}{|c|}{ Infants of birth weight $<1000 \mathrm{~g}(n=118)$} \\
\hline Occurrence & $26(22)$ & $53(45)$ & $92(78)$ \\
\hline \multicolumn{4}{|l|}{ Concentration recorded on } \\
\hline$\geqslant 3$ days & $6(5)$ & $12(10)$ & $46(39)$ \\
\hline \multicolumn{4}{|c|}{ Infants who were small for gestational age $(n=208)$} \\
\hline Occurrence & $22(11)$ & $68(33)$ & $143(69)$ \\
\hline $\begin{array}{l}\text { Concentration recorded on } \\
\geqslant 3 \text { days }\end{array}$ & $4(2)$ & $11(5)$ & $43(21)$ \\
\hline
\end{tabular}

TABLE II - Variation among centres in occurrence of hypoglycaemia (plasma glucose concentration $<2.6 \mathrm{mmol} / \mathrm{l}$ ) in preterm infants. Values are numbers (percentages) of infants

\begin{tabular}{lcc}
\hline & Occurrence & $\begin{array}{c}\text { Hypoglycaemia } \\
\text { measured on } \\
\geqslant 3 \text { days }\end{array}$ \\
\hline $\mathrm{A}(\mathrm{n}=28)$ & $17(61)$ & $1(4)$ \\
$\mathrm{B}^{\star}(\mathrm{n}=156)$ & $83(53)$ & $9(6)$ \\
$\mathrm{C}+(\mathrm{n}=130)$ & $76(59)$ & $14(11)$ \\
$\mathrm{D}^{\star}(\mathrm{n}=279)$ & $203(73)$ & $59(21)$ \\
$\mathrm{E}^{+}(\mathrm{n}=68)$ & $54(79)$ & $21(31)$ \\
\hline
\end{tabular}

Comparable major regional referral units.

tComparable units.

hypoglycaemia, and in particular the number of days on which it was identified (table I), was probably an underestimate. The number of infants who contributed three, seven, and 14 blood samples, regardless of glucose concentration, was 529, 364, and 132 respectively. This potential for underdiagnosis, however, was offset by the likelihood that hypoglycaemia occurred principally in small, sick infants, who were the ones monitored intensively.

Table II shows that among the five centres studied the percentage of infants with plasma glucose concentrations $<2.6 \mathrm{mmol} / \mathrm{l}$ that persisted on three or more days varied 10 -fold (from $4 \%$ to $31 \%$ ). In centres $B$ and $\mathrm{D}$ (comparable regional referral units) the values were $6 \%(9 / 156$ cases $)$ and $21 \%(59 / 279$ cases $)(p<0.0001)$. In those infants with hypoglycaemia (plasma glucose concentration $<2.6 \mathrm{mmol} / \mathrm{l}$ ) the median age at onset was 2 days (range 1 to 58 days) and the median age when the final value $<2.6 \mathrm{mmol} / \mathrm{l}$ was recorded was 6 days (range 1 to 91 days); such hypoglycaemia was detected beyond 1 month in 60 infants (nearly $10 \%$ of the cohort studied) and beyond two months in 16 infants. Only 31 infants had hypoglycaemia on three or more consecutive days; thus most of the infants with protracted hypoglycaemia had recurrent episodes.

\section{FACTORS ASSOCIATED WITH THE DEVELOPMENT OF} HYPOGLYCAEMIA

Regression models were constructed to examine a range of factors associated with the occurrence of hypoglycaemia or the number of days on which it was recorded (dependent variable) with cut off points of either 1.5 or $2.5 \mathrm{mmol}$ glucose/l. Significant factors $(p<0.01)$ included the centre to which the infant was admitted, a birth weight under $1000 \mathrm{~g}$, a 5 minute Apgar score $<5$, and being small for gestational age. After adjustment for other factors we found that social class, maternal toxaemia, maternal fatness (body mass index - that is, weight/(height $)^{2}$ ), the infant's sex, and the infant's diet were not associated with hypoglycaemia ( $p>0 \cdot 05)$. Gestational diabetes (requiring or not requiring insulin) occurred in only 11 cases, and no infant developed a plasma glucose concentration of $<1.5 \mathrm{mmol} / \mathrm{l}$, perhaps reflecting the preventive measures taken in this known high risk group. Infants who developed hypoglycaemia to any extent had a smaller body mass index at birth than those who did not - for instance, with $1.5 \mathrm{mmol} / \mathrm{l}$ as the cut off the mean (SE) body mass index was $8.6(0.05) \mathrm{kg} / \mathrm{m}^{2}$ compared with $7.9(0 \cdot 11) \mathrm{kg} / \mathrm{m}^{2}(\mathrm{p}<0.001)$.

\section{SYMPTOMATIC AND ASYMPTOMATIC HYPOGLYCAEMIA}

Of the 433 infants with a plasma glucose concentration $<2 \cdot 6 \mathrm{mmol} / \mathrm{l}, 222 \mathrm{had}$ one or more of the following symptoms, which have been associated with hypoglycaemia': recurrent apnoea (164), vomiting (93), "jitteriness" (19), and convulsions (13). These symptoms, however, were found to be equally prevalent in the 228 infants without hypoglycaemia at equivalent postnatal age and after adjustment for birth weight and respiratory illness. In only five cases, in which hypoglycaemia was associated with fits, was 
there a convincing causal relation. Analysis of whether symptomatic infants had more neurodevelopmental problems at 18 months (see below) was confounded by the small number of asymptomatic infants with prolonged hypoglycaemia.

\section{DEVELOPMENTAL SCORES AT I 8 MONTHS}

Regression analysis was used to explore a minimum safe plasma glucose concentration in terms of developmental scores at 18 months (corrected age). The Bayley motor and mental development scales (dependent variables) were regressed against days of hypoglycaemia (independent variable) with cut offs for plasma glucose concentrations between 0.5 and $4.0 \mathrm{mmol} / \mathrm{l}$. Further independent variables were introduced to adjust for the infants' sex, gestational age (24-29 weeks $v$ 30-37 weeks), birth weight (as a continuous variable), fetal growth retardation (birth weight $<10$ th centile for gestational age), number of days of mechanical ventilation (as a general measure of illness), number of exchange transfusions, number of proved systemic infections, plasma bilirubin concentrations (above and below and equal to $170 \mu \mathrm{mol} / \mathrm{l})$, Apgar score (0-4 $v$ 5-10), social class, and mothers' educational level. Social class (obtained from the Registrar General's classification) and mother's standard of education (coded as previously reported ${ }^{21}$ ) were linearly related to develop mental scores. Days of ventilation, coded as 0 , $1-6,7-14$, and $>14$, were also linearly related to development. With this model maximum slope (regression coefficient) and significance were seen for motor development $(\mathrm{p}<0.002)$ and mental development $(p<0.005)$ when a cut off of $2.5 \mathrm{mmol} / \mathrm{l}$ was used.

Further modelling showed that reduced developmertal scores were associated independently with the number of days on which plasma glucose concentration was $0-1.5 \mathrm{mmol} / \mathrm{l}(\mathrm{p}<0.01)$ and the number of days on which it was $1.6-2.5 \mathrm{mmol} / \mathrm{l}(\mathrm{p}<0.01)$, whereas no relation was detected when it was in the range $2 \cdot 6-4 \cdot 0$ $\mathrm{mmol} / \mathrm{l}$. For subsequent analyses a plasma glucose concentration of $<2.6 \mathrm{mmol} / \mathrm{l}$ was used to define hypoglycaemia in preterm infants. Data from infants without cerebral palsy showed a progressive fall in developmental scores with increasing number of days on which hypoglycaemia was recorded. When infants with no hypoglycaemia were compared with those exhibiting it on five or more days the mean (SE) scores were $96.1(1.3) v 84.4(3.2)(\mathrm{p}<0.001)$ for motor development and $102 \cdot 0(1 \cdot 5) v 85 \cdot 6(3 \cdot 7)(\mathrm{p}<0.005)$ for mental development.

The slopes and $95 \%$ confidence intervals for the relation between the number of days on which hypoglycaemia was recorded and either motor development $(\mathrm{p}<0.002)$ or mental development $(\mathrm{p}<0.005)$ were defined by regression analysis (figure). The best fit was for developmental scores regressed against the logarithm of days of hypoglycaemia. More detailed analysis showed that when hypoglycaemia had been recorded on three or more days a significant effect on development was detectable and that frequent, moderate hypoglycaemia was associated with a greater developmental deficit than more severe but less frequent hypoglycaemia.

Exploration of interaction effects showed that social class and the mother's standard of education were related to mental (not motor) development independently of hypoglycaemia, and thus the association between hypoglycaemia and poor mental development was not ameliorated if the child came from a high social class background with a well educated mother. Respiratory illness and hypoglycaemia had independent, and hence additive, adverse effects on development. Birth weight, length of gestation, and fetal growth retardation did not influence the develop- mental vulnerability of preterm infants to hypoglycaemia; the age at onset of hypoglycaemia did not influence outcome.

\section{CEREBRAL PALSY AND DEVELOPMENTAL DELAY}

The Bayley mental scale is not satisfactory in infants with cerebral palsy because performance in the test depends on manipulative skills, and infants with this disorder were excluded from the analyses above. We investigated, therefore, whether hypoglycaemia was associated with neurodevelopmental impairment, defined here as either cerebral palsy (39 cases) or developmental delay (Bayley mental or motor score of $\leqslant 70$; 58 cases). Table III shows a highly significant increase in the incidence of neurodevelopmental impairment with the number of days an infant had hypoglycaemia. Table IV shows clinical characteristics and the occurrence of hypoglycaemia in infants with and without such impairment. By logistic regression the number of days on which hypoglycaemia was recorded (independent variable) was regressed against neurodevelopmental outcome (dependent variable), adjusting for all the factors in the models above (table III). The relative risk of neurodevelopmental impairment in infants with hypoglycaemia on five days or more compared with those with no hypoglycaemia was $3 \cdot 5: 1(95 \%$ confidence interval $1 \cdot 3: 1$ to $9 \cdot 4: 1, \mathrm{p}<0 \cdot 02)$. No relation was seen between hypoglycaemia and weight, length, or circumference of the head at 18 months after adjustment for the same factors.

\section{ANALYSIS OF SUBGROUPS AND SAMPLING BIAS}

Table $\mathrm{V}$ shows the reduction in mental and motor scores after five or more days of hypoglycaemia,

TABLE III - Number of days on which hypoglycaemia (plasma glucose concentration $<2.6 \mathrm{mmol} / \mathrm{l}$ ) was recorded related to incidence of neurodevelopmental impairment (cerebral palsy or developmental delay indicated by Bayley motor or mental score $\leqslant 70$ ) at 18 months before and after adjustment for other factors influencing neurodevelopment

\begin{tabular}{lllll}
\hline & \multicolumn{5}{c}{ Days of hypoglycaemia } \\
\cline { 2 - 5 } & \multicolumn{1}{c}{0} & $1-2$ & $3-4$ & $\geqslant 5$ \\
\hline No of cases & $29 / 177$ & $44 / 284$ & $11 / 51$ & $13 / 31^{\star}$ \\
Occurrence (\%) & 16 & 16 & 22 & 42 \\
Adjusted relative risk $v$ & & $1 \cdot 1: 1$ & $2 \cdot 2: 1$ & $3 \cdot 5: 1 \dagger$ \\
\hline non-hypoglycaemic cases & & &
\end{tabular}

${ }^{\star} \chi^{2}$ for trend $=8 \cdot 29, \mathrm{p}<0 \cdot 01$.

$+\mathrm{p}<0 \cdot 02$. Confidence interval for relative risk at $\geqslant 5$ days $=1 \cdot 3: 1$ to $9 \cdot 4: 1$.
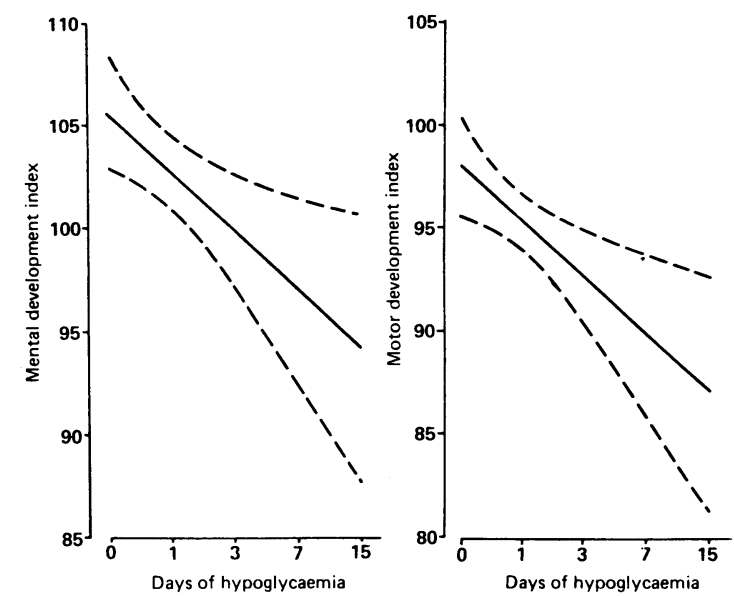

Logarithm of days of recorded hypoglycaemia $<2.6 \mathrm{mmol} / \mathrm{l}$ related to Bayley mental development index and Bayley psychomotor development index at 18 months (corrected age). Regression slopes and 95\% confidence intervals (broken lines) are shown adjusted for days of ventilation, sex, social class, birth weight, and fetal growth retardation. Data shown are for both sexes and all social classes combined and for no ventilation. For infants ventilated for 1-6, 7-14, or $>14$ days subtract 5,10 , or 15 points respectively for mental development index and $4 \cdot 5,9 \cdot 0$, or 13.5 points for psychomotor development index. 
TABLE IV-Clinical characteristics and occurrence of hypoglycaemia (plasma glucose $<2.6 \mathrm{mmol} / \mathrm{l}$ ) in infants according to whether they had neurodevelopmental impairment (cerebral palsy or developmental delay) at 18 months (corrected age)

\begin{tabular}{|c|c|c|}
\hline & \multicolumn{2}{|c|}{ Neurodevelopmental impairment } \\
\hline & $\begin{array}{c}\text { No } \\
(n=446)\end{array}$ & $\begin{array}{c}\text { Yes } \\
(\mathbf{n}=97)\end{array}$ \\
\hline Mean (SE) birth weight (g) & $1380(14)$ & $1302(32)^{\star}$ \\
\hline Mean (SE) gestational age (weeks) & $30 \cdot 9(0 \cdot 1)$ & $29 \cdot 8(0 \cdot 2)^{\star \star \star}$ \\
\hline \multicolumn{3}{|l|}{ No (\%) of infants: } \\
\hline Ventilated for $>6$ days & $66(15)$ & $35(36)^{\star \star \star}$ \\
\hline With apnoea on $>6$ days & $143(32)$ & $45(46)^{\star \star}$ \\
\hline Receiving exchange transfusion & $18(4)$ & $11(11)^{\star \star}$ \\
\hline With proved infection $\dagger$ & $18(4)$ & $16(17)^{\star \star \star}$ \\
\hline \multicolumn{3}{|l|}{ With bilirubin concentration } \\
\hline$>250 \mu \mathrm{mol} / 1$ & $41(9)$ & $15(16)$ \\
\hline \multicolumn{3}{|l|}{ With Apgar score at 5 minutes } \\
\hline$<5$ & $41(9)$ & $10(10)$ \\
\hline Delivered by caesarean section & $237(53)$ & $45(46)$ \\
\hline \multicolumn{3}{|l|}{$\begin{array}{l}\text { No (\%) of infants with } \\
\text { hypoglycaemia on: }\end{array}$} \\
\hline$\geqslant 3$ days & $58(13)$ & $24(25)^{\star \star}$ \\
\hline$\geqslant 5$ days & $18(4)$ & $13(13)^{\star \star \star}$ \\
\hline$\geqslant 7$ days & $9(2)$ & $6(6)^{\star}$ \\
\hline
\end{tabular}

${ }^{\star} \mathrm{p}<0.05,{ }^{\star \star} \mathrm{p}<0.01,{ }^{\star \star \star} \mathrm{p}<0.001$ (by $\chi^{2}$ or Student's $t$ test)

†Positive blood culture.

TABLE $\mathrm{V}-$ Reduction in mental and motor development scores after five or more days of recorded hypoglycaemia (plasma glucose concentration $<2.6 \mathrm{mmol} / \mathrm{l}$ ), adjusted for confounding factors, by degree of monitoring and in each of three largest centres

\begin{tabular}{|c|c|c|c|}
\hline & $\begin{array}{c}\text { No of } \\
\text { subjects }\end{array}$ & $\begin{array}{c}\text { Reduction in } \\
\text { psychomotor } \\
\text { development index } \\
\text { (95\% confidence } \\
\text { interval) }\end{array}$ & $\begin{array}{c}\text { Reduction in } \\
\text { mental } \\
\text { development index } \\
(95 \% \text { confidence } \\
\text { interval })\end{array}$ \\
\hline $\begin{array}{l}\text { Whole population } \\
\text { Degree of monitoring: }\end{array}$ & 503 & $13(20 \text { to } 5)^{\star \star \star}$ & $14(22 \text { to } 6)^{\star \star \star}$ \\
\hline $\begin{array}{l}\text { Intensivef } \\
\text { Non-intensivef }\end{array}$ & $\begin{array}{l}150 \\
353\end{array}$ & $\begin{array}{l}13(23 \text { to } 3)^{\star} \\
13(25 \text { to } 1)^{\star}\end{array}$ & $\begin{array}{l}17(28 \text { to } 6)^{\star \star \star} \\
11(25 \text { to }-3)\end{array}$ \\
\hline $\begin{array}{l}\text { Centre: } \\
\text { B } \\
\text { C } \\
\text { D }\end{array}$ & $\begin{array}{r}94 \\
112 \\
222\end{array}$ & $\begin{array}{l}9(16 \text { to } 2)^{\star} \\
22(39 \text { to } 5)^{\star} \\
12(23 \text { to } 3)^{\star \star \star}\end{array}$ & $\begin{array}{l}37(65 \text { to } 9)^{\star \star} \\
23(42 \text { to } 3)^{\star} \\
9(21 \text { to }-3)\end{array}$ \\
\hline
\end{tabular}

$\star \mathrm{p}<0.05,{ }^{\star} \mathrm{p}<0.01,{ }^{\star \star \star} \mathrm{p}<0.005$ for difference in score between babies observed to have $\geqslant 5$ days of hypoglycaemia compared with those with no hypoglycaemia.

tMean (SD) birth weight 1194 (313) g; median of 15 samples taken/infant. $\ddagger$ Mean (SD) birth weight $1427(295) \mathrm{g}$.

determined by regression. At least one sample was taken daily for the first week (the high risk period for hypoglycaemia), and a median of 15 samples was obtained, from the 150 infants who were monitored intensively. Five or more samples were taken from 155 of the 353 infants who were not monitored intensively. The reduction in motor scores with hypoglycaemia was identical in the non-intensively and intensively monitored groups $(\mathrm{p}<0.02$ in both groups), though there was a trend towards a greater reduction in mental score in those monitored intensively $(p<0.01$ in this group). Overall, however, these data suggested that despite the inevitably greater number of samples obtained from sick, smaller infants the relation between hypoglycaemia and reduced scores was not fundamentally altered by this sampling bias.

When data from the three largest centres $(B, C$, and D) were analysed separately (table V) motor and mental developmental scores after five or more days of hypoglycaemia were reduced (only the reduction in mental development in centre D failed to reach significance). There was a small sampling bias among centres: in centres $\mathrm{C}, \mathrm{B}$, and $\mathrm{D}$ the proportion of infants who had their glucose concentrations determined five or more times was $59 \%, 62 \%$, and $79 \%$ respectively. This ranking was not, however, the same as that for the magnitude of reduction in developmental scores in these centres (table IV) or for the proportion of infants in each centre with hypoglycaemia for three or more days (table II). There were too few infants from centres $\mathrm{A}$ and $\mathrm{E}$ for analysis by individual centre.
Centres B and D conducted routine cerebral ultrasound investigations. We performed a two centre analysis to exclude the possibility that a differential occurrence of parenchymal haemorrhage or intraventricular haemorrhage with ventricular dilatation had confounded our findings as such intracerebral disease might be expected to have a major effect on development. After adjustment for this additional variable the relation between hypoglycaemia and reduced developmental scores or neurodevelopmental impairment was unchanged.

\section{Discussion}

We showed in a large five centre study that pronounced hypoglycaemia (plasma glucose concentration $<1.6 \mathrm{mmol} / \mathrm{l}$ ), which occurred in $28 \%$ of infants whose birth weight was under $1850 \mathrm{~g}$, is now more common in premature babies than was reported 10-20 years ago. ${ }^{19} 20$ Furthermore, moderate hypoglycaemia (plasma glucose concentration under $2.6 \mathrm{mmol} / \mathrm{l}$ ), which is often disregarded, occurred in $67 \%$ of infants, often over prolonged periods (table I), and our data show that even moderate hypoglycaemia is associated with a considerable increase in adverse neurodevelopmental sequelae.

Important hypoglycaemia is commonly said to occur when the plasma glucose concentration is under $1.4 \mathrm{mmol} / \mathrm{l}$ in preterm or low birthweight infants in the first week, under $1.9 \mathrm{mmol} / \mathrm{l}$ in term infants during the first 72 hours, and under $2 \cdot 6 \mathrm{mmol} / 1$ thereafter. ' Such values imply that preterm infants are less prone to hypoglycaemic neurological impairment than term infants, that resistance to such damage is greatest during the immediate postpartum period, and that neonates are less prone to damage than adults. None of these contentions has been adequately supported by data on neurodevelopmental outcome. In this study there was no evidence that birth weight, length of gestation, or postnatal age influenced the observed relation between hypoglycaemia and poor developmental outcome.

Plasma glucose concentrations below $2.6 \mathrm{mmol} / \mathrm{l}$ were associated with reductions in Bayley motor and mental development scores at 18 months, even after adjustment for confounding factors known to influence development. This deficit increased with days of hypoglycaemia at this concentration. It was not possible to obtain daily blood samples throughout the infants' hospital stay, and in some infants in whom hypoglycaemia was recorded on more than five separate days sampling was intermittent. Thus we could not define the precise relation between neurodevelopment and hypoglycaemia when this occurred on more than five days. Nevertheless, when all infants with a plasma glucose concentration under $2.6 \mathrm{mmol} / \mathrm{l}$ on five or more days were compared with infants without hypoglycaemia reductions in mental and motor development scores of 14 and 13 points respectively were observed, even after adjustment for confounders. We showed that there was a significant reduction in scores after hypoglycaemia on three to four days; a large sample size would be needed, however, to detect whether this was so after one or two days of hypoglycaemia.

The importance of such a large reduction in developmental scores at 18 months may be questioned. The predictive value of such early tests in general and the potential for catch up development in infants who develop hypoglycaemia are not well defined, yet some data indicate that Bayley scores at $\mathbf{1 8}$ months correlate with intelligence quotients measured later, ${ }^{23}$ perhaps more convincingly in populations than in individual subjects. This cohort will be assessed again later, when these issues should be largely resolved. Though some uncertainty remains, our finding that when a plasma 
glucose concentration below $2.6 \mathrm{mmol} / \mathrm{l}$ was recorded on five days or more it was associated with a substantially increased risk (3.5-fold) of either cerebral palsy or developmental delay (mental or motor score of 70 or less) is of obvious concern.

The relation between hypoglycaemia and long term neurological damage may be explored either by case matching ${ }^{14} 18$ or, as here, by statistical adjustment for differences between infants with and without hypoglycaemia from the same population. The principal problem with most investigations on this topic has been that sample sizes have been insufficient to detect even quite substantial effects. ${ }^{141618}$ Thus previous reports of the fairly benign nature of mild or asymptomatic hypoglycaemia may have been misleading. We emphasise, however, that the association between modest hypoglycaemia and poor neurodevelopment reported here might not be causal and might reflect our failure to adjust adequately for confounding factors. Nevertheless, our findings must be viewed together with the wealth of consistent data showing that more severe neonatal hypoglycaemia results in severe neurological damage. ${ }^{4 \cdot 9}$ Furthermore, Koh et al showed that when the blood glucose concentration in infants fell below the same threshold as described here $(2.6 \mathrm{mmol} / \mathrm{l})$ cerebral dysfunction occurred, as indicated by measurements of auditory and somatosensory evoked potentials. ${ }^{26}$

Our data are subject to the criticism that more samples were collected from the smallest, most sick infants. Subgroup analysis, however, showed a similar reduction in developmental scores whether or not infants had been intensively monitored. Though we cannot eliminate the possibility that cryptic hypoglycaemia occurred in the well, large, and less frequently monitored infants, if this had been a major problem we would have been unlikely to show such a clear neurodevelopmental disadvantage with observed hypoglycaemia in this subgroup.

Although several studies have emphasised the difference in prognosis between symptomatic and asymptomatic hypoglycaemia, ${ }^{4-101+16}$ our data show the difficulty in making this distinction in infants receiving neonatal intensive care. Half of the infants with plasma glucose concentrations under $2.6 \mathrm{mmol} / \mathrm{l}$ had concurrent apnoea, vomiting, jitteriness, or fits; yet an almost identical proportion of babies without hypoglycaemia had the same symptoms. In very few of the hypoglycaemic infants could the associated symptoms be related convincingly to low plasma glucose concentration.

Factors that we found to be associated with hypoglycaemia, including low birth weight, fetal growth retardation, and low Apgar scores, were predictable, ${ }^{1919} 20$ but the high overall incidence of hypoglycaemia and the number of days on which it occurred were surprising. Several authors have noted the incidence of hypoglycaemia in low birthweight infants. ${ }^{19} 20^{24} 25$ Lubchenco and Bard reported that $15 \%$ of preterm infants of appropriate size for their gestational age had a serum glucose concentration under $1.7 \mathrm{mmol} / \mathrm{l}^{19}$; yet Gutberlet and Cornblath reported that only $1.6 \%$ of infants below $2500 \mathrm{~g}$ became hypoglycaemic. ${ }^{20}$ With a comparable cut off for plasma glucose concentration (under $1.6 \mathrm{mmol} / \mathrm{l}$ ) we found that the incidence of hypoglycaemia in preterm babies who were the appropriate size for their gestational age was $26 \%$, perhaps reflecting the increased proportion of extremely low birthweight infants in our cohort. There is little information, however, with which to compare our data for more moderate hypoglycaemia $(<2.6 \mathrm{mmol} / \mathrm{l})$; its high incidence, with $24 \%$ of infants having it on three to 30 separate days and $14 \%$ having it beyond one month of age, was not expected. Moreover, because sampling was discontinuous in this study our data are probably an underestimate of the true incidence and duration.

This multicentre study perhaps identified a prevailing view among neonatologists that plasma glucose concentrations in the range $1.5-2.5 \mathrm{mmol} / 1$ are of doubtful importance in early life. Nevertheless, the great variation in the number of days on which hypoglycaemia was observed among comparable centres indicates a major inconsistency in the approach to management. Although some paediatricians might regard correction of this degree of hypoglycaemia as excessive, most preterm infants in this study developed hypoglycaemia early, when they still had intravascular lines that would have facilitated accurate control of blood glucose concentrations. We suggest that the data on neurodevelopment presented here indicate an urgent need to reappraise the management of neonatal hypoglycaemia. Because gestational age did not influence the relation between hypoglycaemia and impaired neurodevelopment our conclusions may apply also to the full term neonates. Although further follow up of our cohort will enable us to establish the longer term importance of these findings, it would $b$ w'se not to allow plasma glucose concentrations in preterm, and perhaps full term, infants to remain below $2.6 \mathrm{mmol} / \mathrm{l}$.

We thank Drs M F Bamford, J F B Dossetor, A Boon, R Pearse, and $P$ Crowle at the neonatal units at Ipswich, King's Lynn, Sheffield, and Norwich for their help, and Farley Health Products Limited for financial help.

1 Cornblath M, Schwartz R. Hypoglycaemia in the neonate. In: Schaffer AJ, Markowitz M, eds. Disorders of carbohydrate metabolism in infancy. 2nd ed. Philadelphia: W B Saunders, 1976:155-205.

2 Pagliara AS, Karl JE, Haymond M, Kipnis DM. Hypoglycemia in infancy and childhood. Part I. I Pediatr 1973;82:365-79.

3 Aynsley-Green A, Soltesz G. Metabolic and endocrine disorders. In: Robertson NRC, ed. Textbook of neonatology. London: Churchill Livingstone, 1986:605-21.

4 Beard A, Cornblath M, Gentz J, et al. Neonatal hypoglycemia: a discussion. 7 Pediatr 1971;79:314-24.

5 Anderson JM, Milner RDG, Strich SJ. Effects of neonatal hypoglycaemia on the nervous system: a pathological study. F Neurol Neurosurg Psychiatry
1967;30:295-310.

6 Banker BQ. The neuropathological effects of anoxia and hypoglycaemia in the newborn. Dev Med Child Neurol 1967;9:544-50.

7 Haworth JC. Carbohydrate metabolism in the fetus and the newborn. Pediar Clin North Am 1965;12:573-84.

8 Koivisto $M$, Blanco-Sequeiros $M$, Krause U. Neonatal symptomatic and asymptomatic hypoglycaemia: a follow-up study of 151 children. Dev Med Child Neurol 1972;14:603-14

9 Fluge G. Clinical aspects of neonatal hypoglycaemia. Acta Paediatr Scand 1974;63:826-32.

0 Creery RDG. Hypoglycaemia in the newborn: diagnosis, treatment and prognosis. Dev Med Child Neurol 1966;8:746-54.

11 Smallpeice V, Davies PA. Immediate feeding of premature infants with undiluted breast milk. Lancet 1964;ii:1349-56.

12 Wharton BA, Bower BD. Immediate or later feeding for premature babies? A controlled trial. Lancet 1965;ii:969-72.

13 Griffiths AD. Association of hypoglycaemia with symptoms in the newborn. Arch Dis Child 1968;43:688-94.

14 Raivio KO, Hallman N. Neonatal hypoglycaemia. I. Occurrence of hypoglycaemia in patients with various neonatal disorders. Acta Paediatr Scand caemia in patien.

15 Raivio KO. Neonatal hypoglycaemia. II. A clinical study of 44 idiopathic cases with special reference to corticosteroid treatment. Acta Paediatr Scand 1968;57:540-6.

16 Gentz JCH, Persson B, Zetterstrom R. On the diagnosis of symptomatic neonatal hypoglycaemia. Acta Paediatr Scand 1969;58:449-59.

17 Fluge G. Neurological findings at follow-up in neonatal hypoglycaemia. Acta Paediatr Scand 1975;64:629-34.

18 Griffiths AD, Bryant GM. Assessment of effects of neonatal hypoglycaemia: a study of 41 cases with matched controls. Arch Dis Child 1971;46:819-27.

19 Lubchenco LO, Bard H. Incidence of hypoglycemia in newborn infants classified by birth weight and gestational age. Pediatrics 1971:47:831-8.

20 Gutberlet RL, Cornblath M. Neonatal hypoglycemia revisited. Pediatrics 1976;58:1-17.

21 Lucas A, Gore SM, Cole TJ, et al. A multicentre trial on the feeding of low birthweight infants: effects of diet on early growth. Arch Dis Child 1984;59:722-30.

22 Bayley N. Bayley scales of infant development. New York: Psychological Corporation, 1969

23 Siegel LS. Prematurity and its consequences for the assessment of the very low birthweight infant. Child Dev 1983;54:1176-88.

24 Pildes R, Forbes AE, O'Connor SM, Cornblath M. The incidence of neonatal hypoglycaemia: a completed survey. F Pediatr 1967;70:76-80.

25 Wybregt SH, Reisner SH, Patel RK, Nellhaus G, Cornblath M. The incidence of neonatal hypoglycemia in a nursery for premature infants. $\mathcal{J}$ Pediatr 1964;64:796-802.

26 Koh THHG, Aynsley-Green A, Tarbit M, Eyre JA. Neural dysfunction during hypoglycaemia. Arch Dis Child (in press).

(Accepted 23 August 1988) 